\title{
SISTEM BOMBON: FUNGSIONALISME STRUKTURAL TERHADAP MASYARAKAT KADAZANDUSUN DI KIULU, TUARAN, SABAH
}

\section{(The Bombon System: A Structural Functionalism Study on the Kadazandusun Community in Kiulu, Tuaran, Sabah)}

Jacinta Tangil

jessukm@yahoo.com

Asmiaty Amat*

asmiaty@ums.edu.my

Pusat Penataran Ilmu dan Bahasa, Universiti Malaysia Sabah.

Terbit dalam talian (published online): 1 Januari 2021

Sila rujuk: Jacinta Tangil danAsmiaty Amat.(2021). Sistem Bombon: Fungsionalisme Struktural terhadap Masyarakat Kadazandusun di Kiulu, Tuaran Sabah. Melayu: Jurnal Antarabangsa Dunia Melayu, 14(1), 101-114.

\begin{abstract}
Abstrak
Kajian ini membincangkan amalan sistem bombon yang menjadi tradisi masyarakat Kadazandusun. Sistem bombon merupakan satu kaedah pemuliharaan ikan air tawar yang dilaksanakan sejak zaman nenek moyang masyarakat tersebut. Melalui amalan ini, masyarakat Kadazandusun dapat melestarikan alam sekitar seterusnya dapat memastikan mereka mendapat sumber ikan secara berterusan. Tradisi bombon bertititik tolak daripada kepercayaan tradisional dan hukum adat masyarakat Kadazandusun. Sistem bombon memperlihatkan kearifan tempatan masyarakat Kadazandusun terhadap alam sekitar dan hubungan sesama manusia. Permasalahan kajian ini adalah berkaitan dengan fungsionalisme struktural sistem bombon terhadap kehidupan masyarakat Kadazandusun. Objektif kajian ini adalah untuk melihat fungsi dan peranan amalan sistem bombon dalam kehidupan masyarakat Kadazandusun. Kajian ini dilakukan dengan menggunakan kaedah kajian lapangan. Teknik yang digunakan ialah temu bual, pemerhatian ikut serta dan penelitian dokumen. Hasil kajian menunjukkan bahawa sistem bombon dan masyarakat Kadazandusun berfungsi dan menyokong kelangsungan hidup masingmasing. Amalan sistem bombon menjadi keperluan estetik fungsional bagi komuniti
\end{abstract}

(C) Dewan Bahasa dan Pustaka. 2021. This work is licensed under the term of the Creative Commons Attribution (CC BY) (http://creative commons.org/licenses/by/4.0/)

ISSN 1675-6460 e-ISSN 2682-8049 
pengamal bombon, seterusnya menghidupkan peranannya sebagai penyumbang terhadap nilai dan budaya terhadap masyarakat pengamal. Amalan sistem bombon menonjolkan banyak kesan positif secara tersurat dan tersirat dalam kehidupan masyarakat Kadazandusun membuktikan bahawa amalan tersebut adalah fungsional dan terus relevan dalam kehidupan masyarakat tersebut pada hari ini.

Kata kunci: Kepercayaan tradisional, hukum adat, kearifan tempatan, bombon, Kadazandusun

\begin{abstract}
This study discusses the practice of the bombon system which is a tradition of the Kadazandusun community. The bombon system is a method of conservation of freshwater fish that has been practiced by the Kadazandusun since the time of their ancestors. Through this practice, the Kadazandusun community can preserve their environment, while at the same time ensuring a continuous source of fish. The bombon tradition is based on the traditional beliefs and customary laws of the Kadazandusun people. The bombon system shows the local wisdom of the Kadazandusun community towards the environment and in human relations. The problem around which this study is centred relates to the structural functionalism of the bombon system in the life of the Kadazandusun community. The objective of this study is to look at the function and role of the practice of the bombon system in the life of the Kadazandusun community. This study was conducted via field study, employing interviews, participatory observations and document research. The results show that the bombon system and the Kadazandusun community are functional and support each other's survival. The practice of the bombon system becomes a functional aesthetic requirement for the community of bombon practitioners, furthering its role as a contributor to the values and culture of the practitioner community. The practice of the bombon system, which highlights many implicit and explicit positive effects in the life of the Kadazandusun community, proves that the practice is functional and continues to be relevant to the life of the community today.
\end{abstract}

Keywords: Traditional beliefs, customary laws, local wisdom, bombon, Kadazandusun

\title{
PENDAHULUAN
}

Masyarakat Kadazandusun merupakan penduduk asli yang terbesar di negeri Sabah, dengan populasi satu pertiga daripada keseluruhan jumlah penduduknya. Masyarakat tersebut secara tradisi mengamalkan aktiviti pertanian, terutamanya penanaman padi sawah dan padi bukit (Luping, 2009: 94), mereka juga menjalankan aktiviti berburu 
serta menangkap ikan sungai. Masyarakat tradisional Kadazandusun menganut kepercayaan berbentuk animisme. Kebanyakan aktiviti harian mereka adalah berkaitan dengan sistem kepercayaan mereka. Begitu juga dengan adat dan budaya tradisi mereka yang diwarisi daripada nenek moyang. Dengan bertitik tolak daripada sistem kepercayaan yang diwarisi oleh mereka. Evans (1923) menerangkan bahawa masyarakat Kadazandusun percaya bahawa setiap unsur alam mempunyai semangat ghaib atau penunggu. Oleh itu mereka perlu mengadakan pelbagai persembahan atau ritual agar dapat mewujudkan hubungan yang baik dengan semangat dan penunggu yang dipercayai menghuni tempat-tempat tertentu.

Kepercayaan terhadap semangat atau kuasa luar biasa yang terdapat pada benda atau unsur alam semula jadi menyebabkan masyarakat Kadazandusun sentiasa berusaha untuk menjaga hubungan yang baik dengan alam. Kebanyakan aktiviti tradisi yang dilakukan oleh masyarakat Kadazandusun dilakukan dengan berhati-hati untuk mengelakkan kemarahan semangat ghaib dan penunggu. Mereka percaya bahawa konflik yang wujud antara manusia dengan alam semula jadi boleh menyebabkan semangat atau penunggu yang mendiami sesuatu kawasan atau benda boleh mengakibatkan penyakit, kecelakaan atau malapetaka kepada manusia. Kepercayaan tersebut telah mengikat masyarakat Kadazandusun untuk saling bekerjasama demi mengekalkan hubungan yang baik dengan alam semula jadi (Williams 1965: 90).

Setiap perlakuan yang dikaitkan dengan kepercayaan tradisional masyarakat tersebut akhirnya menjadi adat bagi mereka. Adat dianggap amat penting dalam setiap perjalanan kehidupan masyarakat Kadazandusun. Adat menjadi panduan dan garis panduan tingkah laku masyarakat Kadazandusun. Peraturan-peraturan tertentu diwujudkan sehingga akhirnya menjadi hukum adat bagi masyarakat Kadazandusun. Kepentingan adat dalam seluruh aspek kehidupan masyarakat Kadazandusun digambarkan oleh Luping (2009: 100) sebagai "adat was a way of life." Hukum adat masyarakat Kadazandusun diterima dan diiktiraf oleh pihak kerajaan sebagai Undang-undang Adat Anak Negeri (Jacinta, 2018: 907). Kepatuhan kepada adat itu sendiri akhirnya berjaya membentuk nilai dan norma yang berjaya menyatukan segala tindakan mereka.

Sistem bombon merupakan antara aktiviti budaya masyarakat Kadazandusun yang sinonim dengan hukum adat masyarakat Kadazandusun sehingga hari ini. Pelaksanaan sistem bombon yang diwarisi dari nenek moyang mereka sudah menjadi identiti masyarakat tersebut. Daripada sistem kepercayaan, adat dan hukum adat, amalan sistem bombon turut dilingkari dengan nilai dan norma masyarakat tersebut.

Pelaksanaan bombon telah menjadi amalan budaya yang turut dikaitkan dengan adat, nilai dan norma masyarakat Kadazandusun yang membentuk kearifan tempatan mereka dalam penjagaan alam sekitar. Semua unsur tersebut adalah fungsional, 
saling memberi sumbangan, dan saling terintegrasi. Perubahan yang berlaku dalam satu elemen atau unsur sistem sosial akan turut memberi kesan kepada elemen atau unsur yang lain. Sudah tentu, jika struktur atau bahagiannya tidak berfungsi, secara beransur-ansur struktur itu akan hilang dengan sendirinya. Berdasarkan penjelasan tersebut, tujuan kajian ini adalah untuk menerangkan dan memahami fungsionalisme struktural sistem bombon dalam kehidupan masyarakat Kadazandusun.

\section{KAEDAH DAN TEORI KAJIAN}

Kaedah yang digunakan ialah pemerhatian ikut serta dan temu bual secara formal dan tidak formal. Kajian lapangan dilakukan untuk meneliti amalan bombon yang diamalkan oleh masyarakat Kadazandusun sejak sekian lama. Penelitian difokuskan kepada kumpulan masyarakat Kadazandusun di beberapa buah kampung di Kiulu, Tuaran, Sabah, iaitu Kampung Poturidung, Kampung Malangang dan Kampung Lokub. Keseluruhan penduduk kampung tersebut merupakan masyarakat Kadazandusun dan masih mengamalkan adat tradisi yang dipraktikkan melalui sistem bombon. Kawasan Kiulu terletak dalam kawasan pentadbiran Daerah Tuaran dan mempunyai keluasan 537 kilometer persegi di Pantai Barat Negeri Sabah. Kiulu terletak lebih kurang 60 kilometer dari pusat Bandaraya Kota Kinabalu, iaitu ibu negeri Sabah. Kedudukan Kiulu di bawah kaki Banjaran Crocker dan bersempadan dengan daerah Penampang, Tambunan, Nabalu dan tanah tinggi Ranau telah mempengaruhi bentuk muka bumi Kiulu. Hampir 70 peratus keluasan Kiulu diliputi oleh bentuk muka bumi yang berbukit-bukau (Doket 33 Tuaran: 0106. Arkib Negeri Sabah).

Kajian di lapangan adalah untuk mendapatkan data primer atau data mentah. Dalam kajian ini data primer diperoleh melalui temu bual mendalam serta pemerhatian secara langsung di kawasan lapangan. Amir Hassan (2006: 130) menyatakan bahawa melalui kaedah ini, pengkaji dapat melihat dan mengkaji kejadian sebenar dalam kehidupan sosial. Menurut Mohd Yusri (2017: 89) pula, kaedah pemerhatian ikut serta atau melalui pelibatan penyelidik membolehkannya memahami tingkah laku subjek kajian tersebut secara langsung, menyeluruh, serta dalam situasi sebenar. Interaksi ini bertujuan untuk memperoleh data melalui teknik yang sistematik. Pengkaji juga dapat memperoleh informasi daripada masyarakat itu sendiri dalam situasi sebenar. Melalui kaedah itu juga, perlakuan masyarakat dapat diperhatikan dan dianalisis untuk memahami tingkah laku subjek kajian secara langsung. Melalui kaedah pemerhatian secara langsung, pengkaji juga dapat masuk dan merasai sendiri perjalanan aktiviti budaya yang dikaji, peralatan yang digunakan, cara dan kaedah yang digunakan dalam pelaksanaan sistem bombon. Pengkaji dapat menghayati fungsi sistem bombon dalam kehidupan komuniti pengamal. Kajian ini juga menggunakan 
kaedah temu bual mendalam. Melalui kaedah ini, semua informan yang ditemu bual dapat memberikan maklumat yang diperlukan untuk kajian ini. Informan yang terlibat dalam kajian ini dipilih daripada kalangan mereka yang mempunyai pengalaman dan mahir dalam kegiatan budaya masyarakat Kadazandusun dan mengamalkan hukum adat. Selain itu, ahli komuniti pengamal bombon itu sendiri turut dipilih sebagai informan. Semua informan yang ditemu bual berumur 50 tahun ke atas serta mempunyai kedudukan yang penting dalam masyarakat. Tujuannya adalah untuk memastikan bahawa semua maklumat yang diperoleh adalah sahih dan bermanfaat. Antara informan yang ditemu bual termasuklah ketua anak negeri, ketua kampung, bekas ketua kampung, bekas ketua daerah, bekas pegawai kerajaan, dan budayawan yang kebanyakannya pernah dan masih aktif dan terlibat secara langsung dengan aktiviti budaya yang dikaji.

Kajian ini menggunakan pendekatan teori fungsionalisme struktural, yang menyarankan untuk melihat masyarakat sebagai suatu sistem yang terdiri daripada pelbagai elemen atau unsur sosiobudaya atau struktur dalam kehidupan yang harus berfungsi (fungsional) dan saling berhubung sehingga masyarakat secara keseluruhan dapat menjalankan fungsi mereka dengan harmoni (Beattie, 1979: 79). Antara elemen atau unsur tersebut termasuklah budaya, nilai dan norma, adat, kepercayaan, pendidikan, politik dan keluarga yang merupakan institusi yang menjadi asas kepada sistem sesuatu masyarakat. Semua elemen tersebut saling berhubungan dan menyokong antara satu dengan yang lain (Sanderson, 2000: 9).

Fungsionalisme struktural ialah teori yang memberikan penekanan tentang fungsi perlakuan sosial atau institusi dalam kegiatan yang menyumbang kepada penerusan

Jadual 1 Informan yang ditemu bual.

\begin{tabular}{|c|l|l|c|l|}
\hline Bil. & Nama Informan & \multicolumn{1}{|c|}{ Status dalam Komuniti } & Umur & \multicolumn{1}{|c|}{ Tempat dan Masa } \\
\hline 1 & Binsing Ansumal & Ketua Anak Negeri (KAN) & 67 & Tamparuli: 6 Mac 2018 \\
\hline 2 & Jahid Jahim (Datuk) & $\begin{array}{l}\text { Wakil Rakyat DUN N9/ } \\
\text { Mantan Pegawai Daerah } \\
\text { Tamparuli }\end{array}$ & 59 & $\begin{array}{l}\text { Kg. Bakut, Kiulu: 4 Julai } \\
2018 .\end{array}$ \\
\hline 3 & Juara Gidal & Ketua Kampung & 73 & $\begin{array}{l}\text { Kg. Poturidong, Kiulu: 7 } \\
\text { Mei 2018 }\end{array}$ \\
\hline 4 & Sami Bangud & Bekas Pegawai Kerajaan & 62 & $\begin{array}{l}\text { Kg. Ranap, Kiulu: 14 Julai } \\
2019\end{array}$ \\
\hline 5 & $\begin{array}{l}\text { William Majimbun } \\
\text { (OKK Datuk) }\end{array}$ & $\begin{array}{l}\text { Bekas Ketua Daerah } \\
\text { Mahkamah Anak Negeri } \\
\text { Kota Kinabalu }\end{array}$ & 59 & $\begin{array}{l}\text { Kg. Tatahan, Inanam: 28 } \\
\text { Februari 2019 }\end{array}$ \\
\hline
\end{tabular}


masyarakat. Struktur sosial menentukan kelancaran perjalanan atau keharmonian dan kestabilan masyarakat (Brinkerhoff \& White, 1989: 9). Oleh itu, pendekatan fungsionalisme struktural sesuai diaplikasikan dalam kajian budaya berkaitan dengan pelaksanaan sistem bombon kerana asas pelaksanaan sistem bombon ialah kepercayaan tradisional masyarakat Kadazandusun, yang dipercayai dan dikongsi bersama oleh semua anggota masyarakatnya.

Pendekatan fungsional struktural mengaitkan hubungan antara fungsi dan disfungsi (Ritzer 2010: 253). Fungsi merujuk struktur sosial sesuatu masyarakat yang mengalami kesan positif hasil daripada kefungsian sesuatu masyarakat. Struktur sosial dianggap berfungsi apabila berjaya mengekalkan keadaan yang diharapkan dalam masyarakat. Struktur sosial dikatakan sebagai disfungsi apabila memberikan kesan negatif terhadap masyarakat, akibat tidak mengikut kehendak masyarakat pada satu-satu ketika. Pendekatan fungsionalisme struktural perlu menumpukan kepada kedua-dua hubungan tersebut kerana fungsi dan disfungsi struktur sosial dalam masyarakat adalah saling mempengaruhi (Ibid, 2010: 256). Struktur sosial yang tidak berfungsi atau disfungsi merupakan gangguan fungsional dan biasanya akan hilang secara perlahan-lahan (Umanailo, 2017: 5). Selain itu, pendekatan fungsionalisme struktural juga membincangkan perbezaan dua konsep fungsional, iaitu fungsi ketara yang disebut sebagai fungsi manifes dan fungsi tidak ketara, iaitu fungsi laten (Merton, 1968: 114). Fungsi manifes ialah kesan positif yang nyata dan sedia dimaklumi, diharapkan dan dikehendaki oleh masyarakat. Fungsi laten pula ialah kesan positif yang tidak dijangka ataupun tidak disedari ataupun kesan positif yang tidak disengajakan daripada aktiviti sosial yang dijalankan (Merton, 1968: 117). Menurut Merton lagi (1968: 115), analisis teori fungsionalisme struktural tidak seharusnya hanya tertumpu pada fungsi manifes sahaja tetapi juga perlu meliputi fungsi laten.

\section{SISTEM BOMBON}

Sistem bombon merupakan kearifan tempatan masyarakat Kadazandusun dalam usaha pemuliharaan ikan sungai secara semula jadi. Bombon diamalkan untuk memastikan komuniti pengamal bombon menikmati sumber ikan secara berterusan dan berkekalan. Bombon dalam bahasa Kadazandusun bermaksud "jangan" atau perbuatan yang "dilarang atau ditegah dengan adat" (maklumat diperoleh daripada Sami Bangud, 62 tahun melalui temu bual pada 14 Julai 2019). Melalui kaedah bombon, sebahagian daripada kawasan sungai terutama di sekitar kawasan lubuk dalam akan dikenakan bombon atau sekatan dan larangan menangkap ikan di kawasan tersebut dalam satu tempoh masa tertentu. Kawasan sungai dibahagikan mengikut zon, iaitu 
zon hijau, zon kuning dan zon merah. Kawasan zon kuning terbuka sepanjang tahun. Penduduk boleh menangkap ikan dan menggunakan kawasan tersebut untuk tujuan riadah tetapi hanya menggunakan peralatan yang tidak memudaratkan ikan dan kawasan persekitaran. Penggunaan racun kimia dan tuba dilarang sama sekali. Zon kuning ialah bahagian kawasan sungai yang dihadkan penggunaannya. Kawasan tersebut merupakan kawasan pemuliharaan yang hanya dibuka sekali dalam tempoh setahun hingga tiga tahun. Zon merah ialah kawasan larangan sepenuhnya, iaitu kawasan tersebut menjadi kawasan pembiakan ikan. Kawasan bombon dijaga daripada sebarang bentuk pencemaran termasuk pengambilan batuan dan pasir dari kawasan tersebut yang juga tidak dibenarkan. Mereka yang didapati bersalah melanggar peraturan bombon akan dikenakan hukuman dari segi adat.

Tujuan asal pelaksanaan bombon adalah untuk menjaga hubungan dengan makhluk ghaib. Kepercayaan bahawa setiap unsur alam mempunyai semangat dan penunggu menjadikan mereka gerun dan menghormati alam. Amalan bombon secara tidak langsung berjaya membantu memulihara sumber ikan. Melalui kaedah bombon, ikan dapat membiak dan bertambah dalam satu tempoh masa tertentu. Amalan sistem bombon juga dapat memberikan masa kepada ikan-ikan untuk mencapai tahap matang sebelum dituai. Dalam tempoh masa tersebut, anggota komuniti dilarang sama sekali untuk menangkap ikan di kawasan yang telah dikenakan bombon. Kawasan yang dikenakan bombon juga menjadi kawasan larangan daripada sebarang aktiviti sosial kecuali untuk tujuan pembersihan yang dilakukan secara bergotong-royong oleh komuniti pengamal bombon.

Biasanya, ikan-ikan di kawasan bombon akan dituai dalam masa antara setahun hingga tiga tahun sekali, bergantung pada persetujuan bersama semua anggota komuniti pengamal bombon. Pemilihan tarikh dan masa yang sesuai untuk menuai ikan hasil bombon disepakati bersama dengan mengambil kira situasi dan keadaan sosial pada masa itu dan faktor cuaca. Hari menuai ikan atau buka bombon dikenali sebagai maganu bombon dalam bahasa Kadazandusun. Pemilihan hari untuk maganu bombon biasanya mengambil kira keadaan cuaca dan seboleh-bolehnya dilakukan pada hari cuti umum agar semua anggota komuniti pengamal bombon dapat meluangkan masa bersama-sama dalam aktiviti menuai ikan.

Keadaan cuaca yang panas dan kering pada musim kemarau menjadi pilihan untuk menetapkan hari maganu bombon. Cuaca panas yang panjang mengakibatkan air sungai menjadi cetek. Air sungai yang cetek memudahkan proses menangkap ikan dilakukan. Cuaca yang panas juga membolehkan penduduk mengambil kesempatan untuk beriadah beramai-ramai di sungai sambil menikmati ikan yang dituai pada hari tersebut. Selain hidangan berasaskan ikan, makanan tradisional lain turut disediakan 
oleh anggota komuniti. Hari maganu bombon dianggap seperti pesta kecil atau hari keluarga oleh anggota komuniti.

Peralatan menangkap ikan tradisional sahaja yang dibenarkan pada hari maganu bombon. Antara peralatan yang digunakan termasuklah pancing, pukat (rambat atau jala), jaring, bubu, siyud dan pana' ikan. Semua bentuk tuba tumbuhan, racun atau bahan kimia dan bom ikan adalah diharamkan di kawasan bombon kerana penggunaannya boleh merosakkan dan mencemarkan kawasan sungai serta boleh mengakibatkan kepupusan ikan. Semua ikan yang ditangkap pada hari maganu bombon dibahagikan sama rata kepada semua penduduk. Melalui amalan sistem bombon, semua anggota komuniti pengamal bombon akan mendapat bahagian ikan masing-masing.

Dalam kehidupan masyarakat Kadazandusun, adat bukan sahaja penting dalam pengurusan sumber alam tetapi juga dalam setiap proses kehidupan mereka. Adat merupakan satu sistem perundangan tradisional yang merangkumi satu set kepercayaan dan nilai yang mempengaruhi semua aspek kehidupan. Adat juga merupakan satu set peraturan dan prinsip yang tidak tertulis yang merangkumi seluruh kehidupan termasuk hubungan antara manusia dengan manusia dan antara manusia dengan dunia ghaib. Dalam pengurusan sumber alam, adat melibatkan banyak upacara yang bertujuan untuk pemuliharaan. Upacara-upacara yang diadakan bertujuan untuk mewujudkan hubungan yang baik dengan dunia semangat ghaib yang dipercayai mendiami alam ini (Segundad, 2004: 181).

Bombon pada asalnya dilaksanakan secara kecil-kecilan atau hanya melibatkan kawasan milik individu. Pemilik bombon menjaga kawasan bombon daripada dicerobohi kerana dikhuatiri pengunjung lemas dalam kawasan lubuk yang bukan sahaja dalam tetapi dipercayai mempunyai penunggu yang "boleh" menyebabkan malapetaka. Kawasan lubuk sebenarnya kawasan yang dikenakan bombon kerana merupakan kawasan pembiakan ikan. Pemilik bombon hanya akan membuka bombon pada waktu yang telah ditetapkan dan dilakukan bersama-sama seluruh penduduk agar ikan dapat dinikmati bersama. Sebelum kawasan bombon dibuka, ritual diadakan bertujuan "menenangkan" penunggu atau semangat di kawasan tersebut, agar tidak terkejut dan terganggu dengan kehadiran penduduk kampung. Ritual turut berfungsi untuk menjauhkan bala agar penduduk tidak ditimpa musibah semasa menangkap ikan pada waktu tersebut. Aktiviti menangkap ikan dilakukan secara beramai-ramai dan bekerjasama agar dapat mengelakkan kemalangan berlaku. Selepas itu, kawasan tersebut akan dibombon semula. Penduduk tidak dibenarkan masuk ke kawasan tersebut tanpa izin. Hukuman dari segi adat akan dikenakan terhadap penceroboh. Hukuman dari segi adat dikenakan sebagai pampasan kepada pemilik bombon dan untuk mengelakkan kemarahan penunggu atau semangat di kawasan yang dikenakan bombon (Jacinta \& Asmiaty, 2020). 
Sistem bombon merupakan aktiviti yang memerlukan pelibatan dan kerjasama semua penduduk untuk menjayakannya. Setiap orang memainkan peranan masingmasing dari awal proses sistem tersebut bermula. Setiap orang perlu memastikan tidak berlaku sebarang bentuk pencemaran atau pencerobohan di kawasan bombon. Setiap anggota pengamal bombon menjadi mata dan telinga yang cekap yang akan melaporkan kepada ketua kampung sekiranya berlaku keadaan sedemikian. Semua pengamal bombon bekerjasama menyumbangkan tenaga dan bergotong-royong membersihkan kawasan bombon dan maganu bombon. Setiap orang berusaha melakukan sesuatu mengikut kudrat dan kemahiran masing-masing. Bagi anggota yang tidak dapat hadir pada hari maganu bombon akibat kekangan kerja, uzur (tua) atau sakit dan kurang upaya, mereka tetap mempunyai peranan dengan memberikan sumbangan dari segi kewangan untuk membantu pelaksanaan sistem bombon. Oleh sebab itu, semua anggota layak mendapat pembahagian ikan hasil tuaian bombon. Selepas semua proses pembahagian ikan selesai pada hari maganu bombon, kawasan persekitaran sungai akan dibersihkan, maka kawasan tersebut menjadi kawasan larangan semula dan sistem bombon diteruskan (Jacinta \& Asmiaty, 2020).

Pada hari ini pengetahuan tentang pengurusan sungai secara semula jadi yang diamalkan melalui sistem bombon dikongsi bersama dengan masyarakat luar. Pihak Jabatan Perikanan negeri Sabah dan badan bukan kerajaan berusaha memperkenalkan dan berkongsi manfaat sistem bombon kepada masyarakat luar. Ternyata adat dan hukum adat yang melingkari sistem bombon sebenarnya tidak menjadi penghalang kepada amalan tersebut apabila sistem tersebut turut diusahakan di Taiwan (Lin, 2013) dan di Sarawak yang dikenali sebagai tagang (Angelina et al., 2017).

\section{FUNGSIONALISME STRUKTURAL SISTEM BOMBON}

\section{Fungsi}

Sistem bombon masih terus diamalkan secara turun-temurun oleh masyarakat Kadazandusun yang menunjukkan bahawa amalan tersebut sangat fungsional dalam kehidupan komuniti pengamal. Amalan bombon berintegrasi dan disokong oleh elemen dan unsur sosiobudaya lain seperti kepercayaan, adat, nilai dan norma masyarakat Kadazandusun. Semua elemen dan unsur sosiobudaya yang berintegrasi menjadikan sistem bombon amat fungsional dalam kehidupan komuniti pengamal kerana berjaya menggariskan peraturan berbentuk hukum adat yang seragam dan diterima bersama oleh seluruh ahli komuniti. Keadaan tersebut juga membolehkan komuniti pengamal sistem bombon mengawal tingkah laku anggota komuniti daripada melakukan perlanggaran adat sistem bombon. 


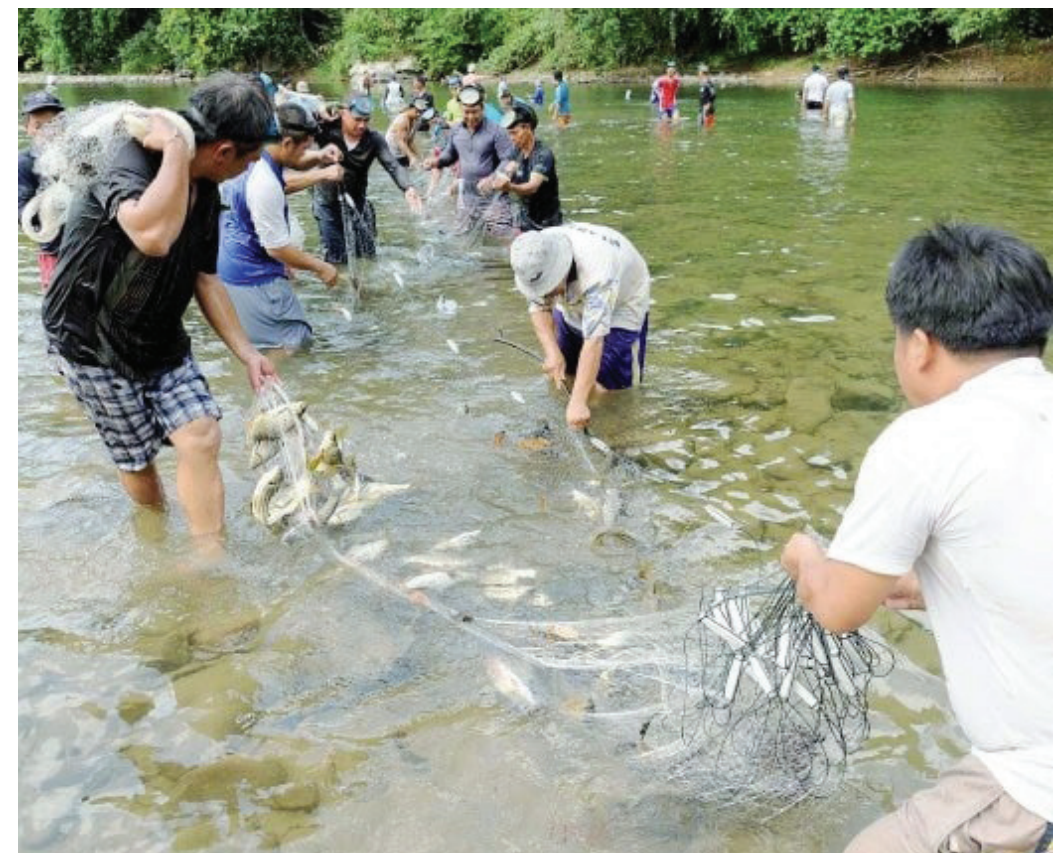

Rajah 1 Masyarakat Kadazandusun sedang menangkap ikan hasil tuaian daripada sistem bombon.

Peraturan bombon sudah menjadi amalan yang sebati dengan kehidupan mereka. Pelanggaran peraturan bombon bermakna melanggar adat, dan mereka yang melanggar adat akan diadili oleh ketua kampung. Hukuman pelanggaran adat bombon sangat tinggi. Mengikut adat masyarakat Kadazandusun, hukumannya seekor kerbau atau bersamaan dengan wang tunai berjumlah tiga ribu ringgit. Semua peralatan menangkap ikan penceroboh juga akan dirampas.

Acara buka bombon menjadi aktiviti yang ditunggu-tunggu oleh seluruh ahli komuniti pengamal. Acara tersebut diadakan setahun hingga tiga tahun sekali bergantung pada keadaan semasa dan persetujuan bersama dengan komuniti. Terdapat juga kampung yang memiliki lebih daripada satu kawasan bombon, oleh itu komuniti ini mengadakan aktiviti buka bombon sehingga dua kali setahun.

\section{Disfungsi}

Disfungsi dalam teori fungsionalisme struktural yang ditekankan Merton ialah perubahan yang berlaku terhadap satu elemen atau unsur sosiobudaya sehingga tidak lagi dapat memberikan sumbangan yang positif dan dianggap sebagai gangguan terhadap masyarakat (Umanailo, 2017: 4). Dalam kajian ini, sistem 
bombon dikatakan mengalami gangguan apabila sistem kepercayaan yang menjadi salah satu elemen atau unsur yang menyokongnya mengalami perubahan apabila masyarakat Kadazandusun mula menerima agama besar seperti Kristian dan Islam. Mereka seterusnya mula menolak kepercayaan animisme secara perlahan-lahan. Disfungsi sistem kepercayaan animisme masyarakat Kadazandusun turut mengubah pandangan dunia masyarakat Kadazandusun, dan turut mengubah fungsi dan sistem nilai bombon dan komuniti pengamal. Andaian fungsionalisme struktural ialah setiap elemen atau unsur sosiobudaya dalam sistem sosial tidak berfungsi terhadap bahagian dan struktur yang lain, elemen atau unsur tersebut akan hilang dengan sendirinya. Maka, sistem kepercayaan tradisional masyarakat kadazandusun akhirnya diganti oleh sistem nilai baharu yang bersifat lebih universal.

\section{Fungsi Manifes}

Fungsi manifes ialah kesan positif yang nyata dan sedia dimaklumi, diharapkan dan dikehendaki oleh masyarakat (Merton, 1968: 117). Amalan bombon pada awalnya berjaya mendoktrin hubungan antara manusia dengan dunia semangat ghaib. Bombon yang diamalkan secara kecil-kecil bertujuan untuk mengawal kawasan sungai yang dikhuatiri dijaga oleh semangat ghaib. Jika kawasan ini diceroboh boleh menimbulkan kemarahan penunggu kawasan tersebut sehingga menyebabkan kecelakaan atau mala petaka berlaku. Amalan bombon berjaya mengawal pencemaran dan memulihara sumber ikan di kawasan tersebut.

Kini, amalan bombon diteruskan dalam skala kawasan bombon yang lebih besar dan penglibatan seluruh anggota komuniti. Bombon milik bersama komuniti dan menjadi tanggungjawab semua anggota pengamalnya untuk meneruskan kelestariannya. Amalan bombon memberikan kelebihan kepada komuniti pengamal untuk menikmati ikan yang bernilai tinggi di pasaran seperti kan pelian atau pait (juga dikenali sebagai ikan kelah atau Mahseer dalam Bahasa Inggeris) selain ikan barob, salap, saraie, kaloi dan sinsilog, iaitu sejenis belut sungai (Jacinta Tangil \& Asmiaty Amat, 2020)

\section{Fungsi Laten}

Fungsi laten pula ialah kesan positif yang tidak dijangka ataupun tidak disedari ataupun kesan positif yang tidak disengajakan akibat aktiviti sosial yang dijalankan (Poloma, 2003: 40). Banyak fungsi laten dapat dikesan melalui amalan bombon. Sistem bombon merupakan kearifan tempatan masyarakat Kadazandusun yang telah menjadi warisan budaya yang tidak ternilai pada hari ini. Antara fungsi laten sistem bombon ialah kejayaan mendidik masyarakat untuk memulihara dan memelihara 
sungai serta persekitaran sungai. Amalan bombon berjaya memastikan kawasan sungai bebas daripada sebarang pencemaran. Hal ini seterusnya membantu menjaga indeks kualiti air sungai yang bersih untuk kehidupan. Pelaksanaan sistem bombon dapat mengekalkan keseimbangan alam seterusnya memastikan penghasilan ikan yang berlipat kali ganda. Pelaksanaan sistem bombon menyumbang kepada pelestarian alam.

Amalan bombon juga membantu komuniti pengamal menguruskan sumber perikanan mereka dengan baik. Komuniti dididik untuk menjaga sumber perikanan mereka melalui pembahagian zon penangkapan ikan. Pengehadan kawasan menangkap ikan membantu proses pembiakan dan pembesaran ikan untuk memastikan komuniti pengamal mendapatkan sumber ikan yang berkualiti secara berterusan. Sumber ikan juga diambil hanya mengikut keperluan komuniti sahaja. Melalui amalan bombon juga, komuniti pengamal dididik untuk berkongsi hasil tuaian ikan yang diperoleh pada hari buka bombon. Semua anggota komuniti mendapat bahagian masing-masing.

Sistem bombon telah diiktiraf sebagai satu kaedah pemuliharaan ikan air tawar secara tradisional yang paling berkesan oleh pihak Jabatan Perikanan negeri Sabah pada tahun 2001 (Wong et al., 2009). Melalui pengiktirafan tersebut, sistem bombon telah diangkat sebagai satu sistem pengurusan pintar (smart partnership) antara pihak kerajaan dengan komuniti pengamal bombon. Pihak kerajaan (melalui Jabatan Perikanan negeri Sabah) memberikan bantuan dari segi teknikal, khidmat nasihat dan bantuan kewangan untuk mewujudkan pengurusan sistem bombon dengan lebih sistematik. Penglibatan pihak kerajaan dalam sistem bombon telah memberikan ruang baharu kepada komuniti pengamal untuk menjana pendapatan.

Sistem bombon membantu meningkatkan sumber ekonomi anggota pengamal bombon dengan memperkenalkan beberapa aktiviti berbayar kepada pengunjung luar seperti aktiviti pancing dan lepas, spa (mandi) bersama ikan dan aktiviti berakit di kawasan sungai. Aktiviti tersebut turut membuka peluang pekerjaan kepada anggota komuniti pengamal seperti bekerja sebagai pemandu pelancong dan pekerja pusat rekreasi berasaskan sistem bombon. Anggota komuniti turut dapat mengambil kesempatan membuka gerai-gerai makan dan kraftangan serta rumah inap desa di kawasan bombon yang dikunjungi oleh masyarakat luar.

Manfaat pelaksanaan sistem bombon yang paling penting adalah sebagai agen penyatuan seluruh komuniti pengamal. Sebagai aktiviti sosial yang dikaitkan dengan kepercayaan tradisional masyarakat tersebut, sistem bombon tidak dapat dipisahkan daripada hukum adat. Jika dahulu aktiviti budaya ini disaluti dengan sistem kepercayaan tradisional, namun pada hari ini, sistem bombon memperlihatkan perubahan nilai melalui pelaksanaannya. Sistem bombon terus diamalkan sehingga kini dengan terjemahan nilai yang sesuai dengan kehidupan anggota komuniti 
pengamal. Pelaksanaan sistem bombon telah berjaya menyemai dan menyerlahkan nilai dan norma masyarakat Kadazandusun. Amalan sistem bombon pada hari ini disokong oleh oleh hukum adat dan diperkuat oleh Enakmen Perikanan Darat dan Akuakultur 2003 yang telah diluluskan oleh kabinet negeri Sabah pada tahun 2003. Sistem bombon yang merupakan kearifan tempatan masyarakat Kadazandusun yang menjadi sumbangan yang amat bermakna dan membanggakan masyarakat Kadazandusun apabila pengetahuan tersebut dikongsi dan diamalkan oleh masyarakat luar. Perkongsian pengetahuan tersebut bermakna, masyarakat luar turut berpeluang mendapat manfaat daripada amalan tersebut (Jacinta \& Asmiaty, 2020).

\section{KESIMPULAN}

Berdasarkan hasil kajian, dapat disimpulkan bahawa sistem bombon merupakan amalan nenek moyang masyarakat Kadazandusun yang dilaksanakan sehingga hari ini. Kawasan sungai yang dikenakan bombon dibuka untuk tujuan penangkapan ikan antara setahun hingga tiga tahun sekali, bergantung pada persetujuan bersama ahli komuniti pengamal. Hukum adat yang melingkari amalan bombon juga diteruskan sehingga kini. Banyak kesan positif diperoleh hasil daripada amalan bombon, sama ada secara tersurat atau tersirat yang disebut sebagai fungsi manifes dan fungsi laten dalam kajian teori fungsionalisme struktural. Hal ini menunjukkan bahawa sistem bombon sangat fungsional dalam kehidupan masyarakat Kadazandusun. Sistem bombon mengalami disfungsi apabila berlaku perubahan dalam sistem kepercayaan masyarakat Kadazandusun. Namun begitu, demi kelangsungan sistem bombon dan untuk mencapai keseimbangan, kepercayaan animisme yang mengikat amalan tersebut mengalami perubahan dengan penerapan nilai-nilai murni yang baharu. Amalan ritual dan peranan golongan bobolian dalam sistem bombon akhirnya hilang dengan sendiri. Hal ini menjadikan kedua-dua kumpulan tersebut berfungsi dan saling memberikan sumbangan.

\section{RUJUKAN}

Angelina Ansley, Wong Swee Kiong, Spencer Empading Sanggin. (2017). Tagang System and the Benefits to the Community at Kampung Terbat Mawang, Serian, Sarawak. Journal of Borneo Kalimantan. JBK Volume 3 (issues 2) December 2017. Institute of Borneo Studies. Universiti Malaysia Sarawak.

Beattie, J. (1979). Lain-lain Kebudayaan. Kuala Lumpur: Dewan Bahasa dan Budaya. Doket 33 Tuaran: 0106. Arkib Negeri Sabah.

Er, A. C., Sivapalan Selvadurai, Lyndon, N., Chong, S. T., Adam, J. H., Mohd Fuad Mat Jali., Hamzah Jusoh. (2012). The Evolvement of Tagal on Ecotourism and Environmental 
MELAYU: JURNAL ANTARABANGSA DUNIA MELAYU JILID 14 BIL.1 JANUARI 2021

Conservation: A Case Study in Kampong Luanti Baru, Sabah. Advances in Natural and Applied Sciences, 6(1), 61-64.

Evans, I. H. N. (1923). Studies in Religion, Folk-Lore and Custom in British North Borneo and the Malay Peninsula. Cambridge: Cambridge University Press.

Evelina L. W. (2016). Vertical Communication Based on Local Wisdom: A Study of World Class University. Pertanika Journal Social Sciences \& Humanities, 24, 59-70. Diakses daripada https://www.researchgate.net/publication/335946821

Jacinta Tangil. (2020). Kearifan Tempatan dalam Sistem Bombon oleh Masyarakat Kadazandusun di Kiulu, Tuaran, Sabah. Malaysian Journal of Social Sciences and Humanities (MJSSH) Vol 5, Issue 2. Februari 2020.

Jacinta Tangil. (2020). Perubahan Sistem Nilai dalam Sistem Bombon yang diamalan oleh Masyarakat Kadazandusun di Kiulu, Tuaran, Sabah. Malaysian Journal of Social Sciences and Humanities (MJSSH) Vol 5, Issue 10. Oktober 2020. Kamus Dwibahasa Melayu - Inggeris Dewan. (2012). Kuala Lumpur: Dewan Bahasa dan Pustaka.

Lin, C. H. (2013). From the Experience of Sabah to Figure Out the Potentials and Challenges to Implement Iccas in Taiwan - The Case Studies Oo Stream Conservation. Taiwan: National Taiwan University.

Luping, H. J. (2009b). Indigenous Ethnic Communities of Sabah, the KadazanDusun. Kuala Lumpur: Kementerian Maklumat, Komunikasi, dan Kebudayaan Malaysia. 17

Merton, R.K. (1968). Social Theory and Social Structure. United States of America: The Press Free.

Poloma, M. M. (1993). Teori Sosiologi Kontemporer. Jakarta: Raja Grafindo1993). Teori Sosiologi Kontemporer. Jakarta: Raja Grafindo.

Ritzer, G. 2010. Sociological Theory (8th Edition). New York: McGraw-Hill.

Sanderson, S. K., 2000, Macro sociology, Jakarta, Grafindo.

Segundad, P. (2004). Biodiversity and tradition in Malaysia. In R. S. Gottlieb (ed.). This Sacred Earth: Religion, Nature, Environment (180-185). Great Britain: Routledge.

Umanailo, M. C. B. (2017). Talcot Parson and Robert K Merton. Diakses daripada https://www.researchgate.net/publication/336753648_TALCOT_PARSON_AND_ ROBERT_K_MERTON/link/5db77c55299bfla47bf9cfe-1/download doi.org/10.31219/ osf.io/9pmt3

Williams, T. R. (1965). The Dusun: A North Borneo society. New York: John Wiley \& Sons. Wong, J. Z., Etoh, S., \& Sujang, A. B. (2009). Toward sustainable Community Based Fishery Resources Management: The Tagal System of Sabah, Malaysia. Southeast Asian Fisheries Development Center, 7(2), 18-23. Diakses daripada http://repository. seafdec.org/bitstream/handle/20.500.12066/791/sp7-2\%20tagal\%20system $\% 20$ of $\% 20$ sabah $\% 20$ malaysia.pdf? sequence $=1$

Tarikh Peroleh (received): 28 Ogos 2020

Tarikh Terima (accepted): 08 Disember 2020 